\title{
Clinical applications of immunofixation: detection and quantitation of complement activation
}

\author{
JT WHICHER,* J HIGGINSON, * PG RICHES, $\dagger$ AND S RADFORD \\ From the *Department of Chemical Pathology, Bristol Royal Infirmary, Bristol, $\uparrow$ Supra Regional Protein \\ Reference Unit, Westminster Hospital, London, and $\ddagger$ Department of Anaesthetics, Southmead Hospital, \\ Bristol, UK
}

SUMMARY The methods currently in use for the detection and quantitation of complement activation products are slow and time consuming. We describe a method utilising immunofixation after agarose or cellulose acetate membrane electrophoresis which allows large batches of samples to be screened rapidly for the presence of activation products of $\mathrm{C} 3$ and factor B. Further, after immunofixation on agarose the conversion product may be quantitated by densitometry. This method gives similar results to those obtained by crossed immunoelectrophoresis. Using both this technique and crossed immunoelectrophoresis we have been able to confirm that $\mathrm{C} 4$ activation occurs during electrophoresis in the absence of EDTA and that in the presence of EDTA it is not demonstrable even in patients with active immune complex disease.

Activation of the complement system results in the formation of fragments of various components of complement. Detection of such fragments in plasma or serum by immunochemical techniques has been widely used as an index of the involvement of complement in disease, ${ }^{1}$ and it has been suggested that their presence correlates with disease activity better than total component concentrations. ${ }^{2}$ The components that have been most studied are $\mathrm{C} 3, \mathrm{C} 4$, and factor $\mathrm{B}(\mathrm{C} 3$ proactivator, glycine rich $\beta$-glycoprotein (GBG)).

The presence of $\mathrm{C} 3$ activation products is a sensitive index of activation of the complement system as C3 is involved in both the classical and alternative pathways. Activation of $\mathrm{C} 3$ results in the production of two biologically important effector molecules, $\mathrm{C} 3 \mathrm{a}$ and $\mathrm{C} 3 \mathrm{~b}$. The latter is broken down by a C3b inactivator (C3INA or KAF) to C3c and C3d. ${ }^{3}$

$\mathrm{C} 4$ is similarly converted to $\mathrm{C} 4 \mathrm{a}$ and $\mathrm{C} 4 \mathrm{~b}$ by the proteolytic action of C1s during activation of the classical pathway. 4

Factor $B$ is broken down in the presence of magnesium ions and factor $D(C 3$ proactivator convertase) to glycine rich $a$-glycoprotein (GAG), a fragment with alpha mobility, and to glycine rich $\gamma$-glycoprotein, C3 activator (GGG), a fragment with gamma mobility. Activation of factor $B$ may be

Received for publication 10 October 1979 due to non-immune activation of the alternative pathway or to feedback activation by C3b. ${ }^{5}$

The activation of complement components has been studied by crossed immunoelectrophoresis, ${ }^{6}$ counter immunoelectrophoresis, ${ }^{7}$ immunoelectrophoresis, ${ }^{8}$ and with the use of antisera directed against specific fragments. ${ }^{9}$

We describe a method of studying $\mathrm{C} 3, \mathrm{C} 4$, and factor $B$ by immunofixation, which allows not only the detection of activation products but also quantitation by densitometry. It has the merit of enabling large numbers of samples to be examined rapidly with considerable economy of antiserum consumption.

\section{Material and methods}

\section{AGAROSE}

\section{Electrophoresis}

Electrophoresis was carried out in a layer of $1 \%$ agarose (Litex HSA, International Enzymes, Windsor, UK), $1 \mathrm{~mm}$ thick, on polyester film (Minnesota Mining and Manufacturing Co, Minneapolis, Minnesota, USA). The buffer was $0.06 \mathrm{M}$ barbitone with a pH of 8.6 with or without EDTA (see below). Samples for immunofixation with anti-C3, anti-C4, and anti-factor $B$ were applied using a slotted plastic mask (LKB Produkter, Uppsala, Sweden) for $2 \cdot 5,3 \cdot 5$, and 5 minutes respectively. The plastic mask was removed, and 
electrophoresis was carried out for 1 hour at 10 $\mathrm{V} / \mathrm{cm}$ with cooling. Samples for the routine investigation of complement activation were collected into EDTA (see below), separated from the cells within 2 hours, and frozen at $-20^{\circ} \mathrm{C}$ before examination.

\section{Immunofixation}

After electrophoresis the area of gel containing the protein to be immunofixed was overlaid with a cellulose acetate membrane (Sepraphore, Gelman Hawksley, Northampton, UK) soaked in the appropriate antiserum, diluted $1: 2$ with $0.12 \mathrm{M}$ barbitone buffer, pH 8.6 , containing $80 \mathrm{~g} / 1$ of polyethylene glycol 6000 (BDH, Poole, UK). The gels were then incubated for 1 hour at room temperature before the cellulose acetate membrane was removed. Antisera to $\mathrm{C3}$ and $\mathrm{C4}$ were obtained from Dakopatts, Copenhagen, Denmark, and antiserum to factor B from Atlantic Antisera, Westbrook, Maine, USA.

\section{Washing and staining}

The gel was pressed under a filter paper and wad of absorbent material, $1 \mathrm{~cm}$ thick, with a $2 \mathrm{~kg}$ weight placed on top for 15 minutes. The plate was then washed in sodium chloride solution $(50 \mathrm{~g} / \mathrm{l})$ for 2 hours before repressing and drying in a stream of warm air. The gel was stained in a solution of Coomassie brilliant blue R (Searle, High Wycombe, UK) $5 \mathrm{~g} / 1$ in methanol: acetic acid: water, 450: 100: 450. The solvent was used for destaining.

\section{Cellulose acetate membrane (CAM)}

\section{Electrophoresis}

Electrophoresis was carried out using fresh $0.06 \mathrm{M}$ barbitone buffer, $\mathrm{pH} 8.6$, at a constant current of $0.4 \mathrm{~mA} / \mathrm{cm}$ on $150 \times 78 \mathrm{~mm}$ CAM sheets using a multiapplicator. ${ }^{10}$ Plasma samples were diluted 1:5 in barbitone/EDTA to give a final concentration of $0.01 \mathrm{M}$ EDTA and $0.06 \mathrm{M}$ barbitone.

\section{Immunofixation}

Immediately after electrophoresis the whole CAM strip was soaked with $0.5 \mathrm{ml}$ antiserum previously diluted $1: 5$ in phosphate-buffered saline, pH 7.4, containing $40 \mathrm{~g} / 1$ polyethylene glycol 6000 and left for 5 minutes.

\section{Washing and staining}

After immunofixation the CAM was rinsed with tap water and then washed twice (15 minutes each) in normal saline containing one drop/l of the surfactant 'Tween 20 '. Strips were blotted and finally stained in a solution of amido black $2.5 \mathrm{~g} / 1$ in methanol: acetic acid: water, 500: 30: 500 and destained in 5\% glacial acetic acid in methanol.

CROSSED IMMUNOELECTROPHORESIS

Crossed immunoelectrophoresis of $\mathrm{C} 3$ and $\mathrm{C} 4$ was carried out according to Versey. ${ }^{6}$

\section{DENSITOMETRY}

Densitometry was carried out using an integrating densitometer (Densicord, Photovolt Corp, New York, NY, USA).

\section{IN VITRO COMPLEMENT ACTIVATION}

The classical pathway was activated by adding $20 \mu \mathrm{l}$ of anti-albumin (Dakopatts, Copenhagen, Denmark) to $500 \mu \mathrm{l}$ of fresh whole serum and incubating at $37^{\circ} \mathrm{C}$ for 30 minutes. This generated soluble antigen-antibody complexes in antigen excess.

The alternative pathway was activated by adding $20 \mu \mathrm{l}$ of bacterial lipopolysaccharide (Difco Labs, Detroit, Michigan, USA) to $500 \mu$ l of fresh whole serum in the presence of EGTA $(10 \mathrm{~mm})$ and $\mathrm{MgCl}_{2}(0.3 \mathrm{mM})$ and incubating at $37^{\circ} \mathrm{C}$ for about 1 hour. Under these conditions classical pathway activation is blocked.

MEASUREMENT OF TOTAL C3, C4, AND

FACTOR B CONCENTRATIONS

Total concentrations of these complement components were measured by nephelometry using a Hyland PDQ Laser nephelometer with Hyland reagents (Hyland, Costa Mesa, California, USA).

\section{Results}

\section{IDENTIFICATION OF C3 FRAGMENTS AFTER} ELECTROPHORESIS

Immunofixation with anti-C3 of fresh normal plasma containing $0.01 \mathrm{~m}$ EDTA after electrophoresis on agarose showed a single band of native C3 with $\beta_{1}$ mobility (Fig. 1a). Serum in which the classical or alternative pathways had been activated in vitro showed a second band with greater anodal mobility; this corresponds with the anodal peak of C3c seen on crossed immunoelectrophoresis ${ }^{6}$ (Fig. 1b) and is presumed to be $C 3 c$. This anodal band of $\mathrm{C} 3$ activation products is resolved into two parts of equal staining density, and the $\beta_{1}$ band of native $C 3$ is retarded in mobility when electrophoresis is performed on infected samples. Similarly, after electrophoresis and immunofixation on CAM native C3 appeared as a single band with $\beta_{1}$ mobility and the conversion products as a more anodal band.

EFFECT OF EDTA ON C3 ACTIVATION PRODUCTS

In the absence of EDTA slight in vitro $\mathrm{C} 3$ activation 


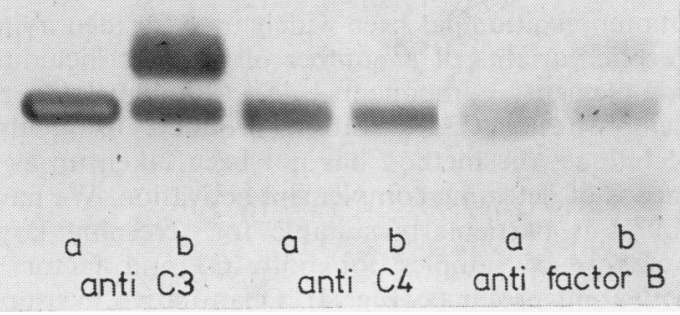

Fig. 1 Immunofixation of fresh EDTA plasma (a) and serum in which the classical pathway had been activated in vitro before the addition of EDTA $(b)$ with antisera to $C 3, C 4$, and factor $B$.

was found to occur in samples not separated within 60 minutes. This was prevented by adding EDTA to the sample in concentrations above $0.002 \mathrm{M}$. In addition, $\mathrm{C} 3$ activation was found to occur during electrophoresis with certain types of agarose unless EDTA was present in the electrophoresis buffer in concentrations above $0.001 \mathrm{M}$. Both these effects could be avoided by adding higher concentrations of EDTA $(0.01 \mathrm{M})$ to the sample alone or by taking blood samples into commercial EDTA tubes (Labco, Marlow, UK) containing $1.5 \mathrm{mg}$ of di potassium EDTA in $1 \mathrm{ml}$ of blood (a concentration of $0.0036 \mathrm{M}$ in whole blood) and adding EDTA to the electrophoresis buffer in a concentration of $0.001 \mathrm{M}$ or above.

The addition of such concentrations of EDTA to serum after complement had been activated in vitro did not affect the mobility or appearance of the anodal $\mathrm{C} 3$ activation band.

Fresh EDTA plasma from a variety of patients with immune complex diseases was examined by immunofixation and by crossed immunoelectrophoresis. Activation products detected by one technique were always detectable by the other.

\section{QUANTITATION OF C3 FRAGMENTS}

The percentage of $\mathrm{C} 3$ present as the anodal activation product was measured by densitometric scanning, and the concentration in plasma was derived from the total $\mathrm{C} 3$ measured by nephelometry, a technique that is not invalidated by the presence of $\mathrm{C} 3$ breakdown products. 11

It is important for quantitative densitometry that the electrophoretogram is not overloaded with protein as this results in an underestimation of the amount owing to inadequate binding of dye. In order to avoid this we immunofixed and scanned a series of serum dilutions to establish a linear dilution response under the conditions described. Protein overloading may be avoided by sample dilution or by decreasing the sample application time.

The quantitative assessment of $\mathrm{C} 3$ activation thus obtained was compared with that derived from crossed immunoelectrophoresis by measuring the area under the $\mathrm{C} 3$ and $\mathrm{C} 3 \mathrm{c}$ peaks; ${ }^{6}$ the results are shown in Figure 2. Fifteen replicate measurements of C3 activation by immunofixation showed a coefficient of variation of $3.76 \%$.

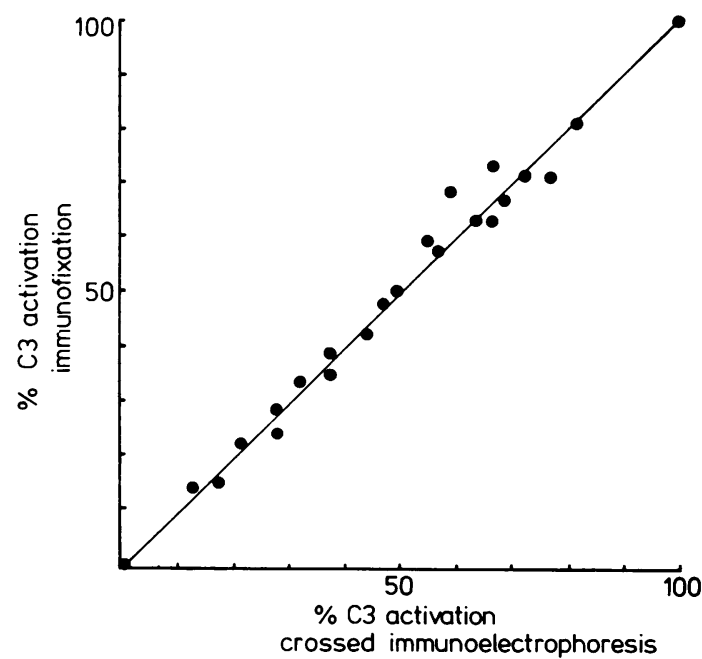

Fig. 2 A comparison of the measurement of $C 3$ activation products by immunofixation and densitometry with crossed immunoelectrophoresis. Complement was activated in serum samples in vitro by the alternative pathway: $r=0.986, Y=1.03 x-0.4$.

IDENTIFICATION OF FACTOR B FRAGMENTS Immunofixation of fresh normal plasma containing $0.01 \mathrm{M}$ EDTA with anti-factor $B$ after electrophoresis on agarose showed a single band of $\beta_{2}$ mobility (Fig. 1). Activation of complement in vitro by either the classical or alternative pathway resulted in the formation of two additional bands; these were also present in samples collected into EDTA from patients with in vivo complement activation (Fig. 1). The fast component with alpha electrophoretic mobility represents GAG while the slow component with gamma mobility represents GGG, that is, C3 activator. Both components are always produced by factor $\mathrm{B}$ activation.

Quantitative estimation of factor B activation products as determined for $\mathrm{C} 3$ revealed low concentrations relative to that of native factor $B$, regardless of the degree of $\mathrm{C} 3$ conversion. Factor $\mathrm{B}$ activation and $\mathrm{C} 3$ activation were invariably present together when this was due to in vitro activation. $\mathrm{C} 3$ activation occurred alone in a number of cases of immune complex disease. 
IMMUNOFIXATION OF C4

Fresh normal plasma containing EDTA in concentrations above $0.08 \mathrm{M}$ showed a single $\mathrm{C} 4$ band after electrophoresis and immunofixation on agarose without EDTA in the buffer (Fig. 1). Serum likewise showed a single band if electrophoresis was carried out in buffer containing EDTA in concentrations greater than 0.008. With decreasing EDTA concentrations in either sample or buffer the C4 band progressively moved to a more anodal position and a cathodal band of $\mathrm{C} 4$ activation products appeared (Fig. 3). These changes represent $\mathrm{C4}$ activation occurring during electrophoresis and were invariably present in the absence of EDTA. If EDTA was present in both sample and buffer lower concentrations were required; an EDTA concentration of 0.002 in the sample and $0.001 \mathrm{M}$ in the buffer was adequate to prevent in vitro $\mathrm{C} 4$ activation. Samples in which $\mathrm{C} 3$ had been activated in vitro by immune complexes (classical pathway) showed only a single band of C4 if EDTA was added to the sample in concentrations above $0.08 \mathrm{M}$ before electrophoresis (Fig. 1). Similarly, EDTA samples from 20 patients with low $\mathrm{C} 4$ concentrations and immune complex disease showed only a single band of $\mathrm{C} 4$.

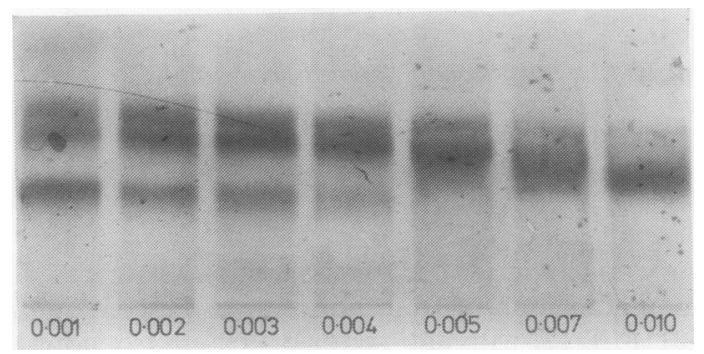

Fig. 3 Effect of EDTA concentrations varying from 0.001 to $0.01 \mathrm{M}$ on appearance of serum immunofixed with antiserum to $C 4$.

\section{Discussion}

Immunofixation has been widely used for identifying genetic variants of a number of proteins including complement components. ${ }^{12} 13$ Although Alper ${ }^{14}$ demonstrated $\mathrm{C} 3$ activation products using this technique, the method has not been taken up as a means of detecting complement activation. We have found it particularly suitable for screening large numbers of samples for both $\mathrm{C} 3$ and factor B activation products (Fig. 4). Quantitative measurements are easily obtained, and the sensitivity of the method is similar to that of crossed immunoelectrophoresis, but it is quicker to perform and requires less antiserum. In the case of factor $B$ activation immunofixation is superior to crossed immunoelectrophoresis as the GGG fragment is more clearly demonstrated.

We were unable to demonstrate $\mathrm{C} 4$ activation products by either immunofixation or crossed immunoelectrophoresis if EDTA was present in adequate concentrations in the sample or electrophoresis buffer. In the absence of EDTA, C4 activation products were always present, the amount varying with the duration and conditions of electrophoresis. It seems probable that the activation occurs during electrophoresis and thus represents an artefact, as suggested by Rosenfeld, ${ }^{15}$ Sjöholm, ${ }^{16}$ and Scharfstein. ${ }^{17}$ Such findings are at variance with those of Versey, ${ }^{6}$ who used the appearance of two C4 bands on crossed immunoelectrophoresis as evidence of in vivo $\mathrm{C} 4$ activation. ${ }^{18}$ We have, however, seen one patient in whom there was a marked increase in $\mathrm{C} 4$ activation products in the absence of EDTA during an acute anaphylactic reaction to a drug; C3 activation in the presence of EDTA was also present. It is thus possible that an increased tendency for $\mathrm{C} 4$ activation to occur during electrophoresis in the absence of EDTA may have biological significance. This has been suggested for $\mathrm{C} 3$ in rheumatoid arthritis by Shadforth and McNaughton ${ }^{19}$ who sug-

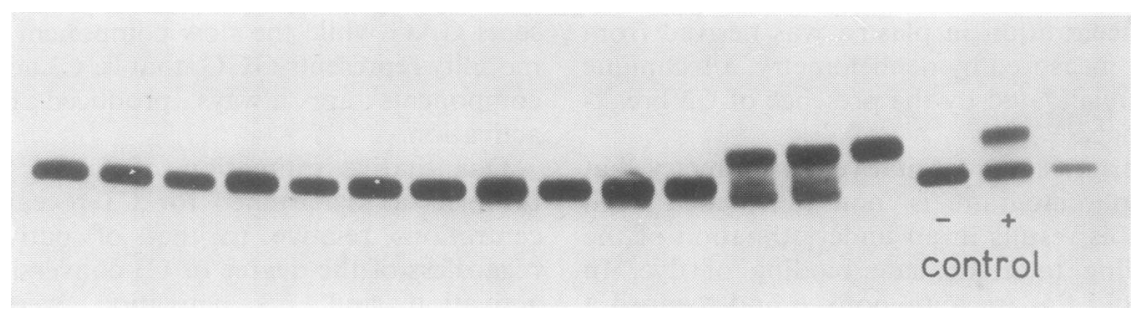

Fig. 4 Example of immunofixation with antiserum to $C 3$ used to screen 15 patients for $C 3$ activation products. A negative control of fresh EDTA plasma and a positive control of serum activated by the classical pathway in vitro are included. 
gested that the $\mathrm{C} 3$ activation seen by Versey in this condition was an electrophoretic artefact due to the absence of EDTA in the electrophoretic system. They did, however, show that this 'artefact' occurred to a greater extent in patients with rheumatoid arthritis than in normals and suggested that this may have pathological significance.

\section{References}

${ }^{1}$ Whicher JT. The value of complement assays in clinical chemistry. Clin Chem 1978;24:7-22.

2 Teisberg $\mathrm{P}$. In vivo activation of $\mathrm{C} 3$ revealed by crossed immunoelectrophoresis as a parameter of immunological activity in disease. Clin Chim Acta 1975;62: 35-41.

${ }^{3}$ Molenaar JL, Müller MAC, Engelfriet CP, Pondman KW. Changes in antigenic properties of human C3 upon activation and conversion by trypsin. J Immunol 1974; 112:1444-51.

${ }^{4}$ Fujita T, Gigli I, Nussenzweig V. Human C4-binding protein. II Role of proteolysis of $\mathrm{C} 4 \mathrm{~b}$ by C3b-inactivator. $J$ Exp Med 1978;148:1044-51.

${ }^{5}$ Fearon DT, Austen FK. Activation of the alternative complement pathway with rabbit erythrocytes by circumvention of the regulatory action of endogenous control proteins. J Exp Med 1977;146:22-3.

- Versey JMB. Automated two-dimensional immunoelectrophoresis and its application to the analysis of C3 and C4 in rheumatoid arthritis and systemic lupus erythematosus (SLE). Ann Clin Biochem 1973;10:100-6.

${ }^{7}$ Arroyave CM, Tan EM. Detection of complement activation by counterimmunoelectrophoresis (CIE). J Immunol Methods 1976;13:101-12.

8 Jordon RE, Day NK, Luckasen JR, Good RA. Complement activation in pemphigus vulgaris blister fluid. Clin Exp Immunol 1973;15:53-63.

- Perrin LH, Lambert PH, Miescher PA. Complement breakdown products in plasma from patients with systemic lupus erythematosus and patients with membranoproliferative or other glomerulonephritis. J Clin Invest $1975 ; 56: 165-76$.

${ }^{10}$ Kohn J. A multi-sample applicator for zone electrophoresis. Clin Chim Acta 1967;18:65-8.

11 Buffone GJ, Lewis SA. Effect of analytical factors on immunochemical reference limits for complement component $\mathrm{C} 3$ in serum of a reference pediatric population. Clin Chem 1977;23:994-9.

12 Alper CA, Boenisch T, Watson L. Genetic polymorphism in human glycine-rich beta-glycoprotein. J Exp Med 1972;135:68-80.

${ }^{13}$ Mauff G, Bender K, Fischer B. Genetic polymorphism of the fourth component of human complement. Vox Sang 1978;34:296-301.

14 Alper CA, Johnson AM. Immunofixation electrophoresis. A technique for the study of protein polymorphism. Vox Sang 1969;17:445-52.

${ }^{15}$ Rosenfeld SI, Ruddy S, Austen KF. Structural polymorphism of the fourth component of human complement. J Clin Invest 1969;48:2283-92.

${ }^{16}$ Sjöholm AG, Laurell AB. Conversion of the fourth complement component studied by crossed immunoelectrophoresis. Clin Exp Immunol 1973;14:515-29.

${ }^{17}$ Scharfstein J, Ferreira A, Gigli I, Nussenzweig V. Human C4-binding protein. I Isolation and characterization. $J$ Exp Med 1978;148:207-22.

${ }^{18}$ Nicolson IC, Ashby PA, Johnson ND, Versey J, Slater L. Boomslang bite with haemorrhage and activation of complement by the alternative pathway. Clin Exp Immunol 1974;16:295-300.

19 Shadforth MF, McNaughton DC. Examination of complement $\mathrm{C} 3$ metabolism in rheumatoid arthritis using 2-dimensional immunoelectrophoresis. Ann Rheum Dis $1978 ; 37: 18-23$.

Requests for reprints to: Dr JT Whicher, Department of Chemical Pathology, Bristol Royal Infirmary, Bristol BS2 8HW, UK. 